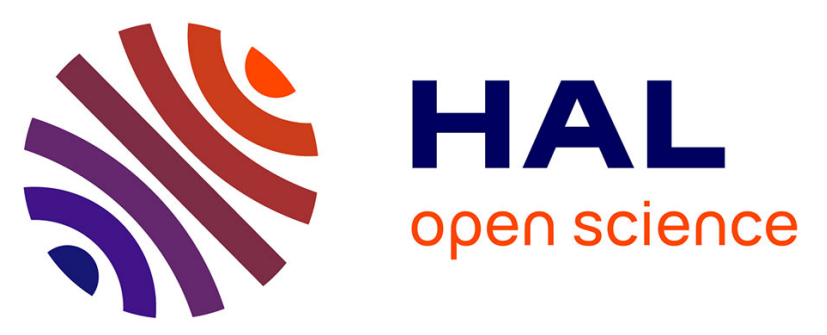

\title{
Management on the basis of the best scientific data or integration of ecological research within management? Lessons learned from the Northern spotted owl saga on the connection between research and management in conservation biology
}

Frédéric Gosselin

\section{To cite this version:}

Frédéric Gosselin. Management on the basis of the best scientific data or integration of ecological research within management? Lessons learned from the Northern spotted owl saga on the connection between research and management in conservation biology. Biodiversity and Conservation, 2009, 18 (4), p. 777 - p. 793 . 10.1007/s10531-008-9449-6 . hal-00454482

\author{
HAL Id: hal-00454482 \\ https://hal.science/hal-00454482
}

Submitted on 8 Feb 2010

HAL is a multi-disciplinary open access archive for the deposit and dissemination of scientific research documents, whether they are published or not. The documents may come from teaching and research institutions in France or abroad, or from public or private research centers.
L'archive ouverte pluridisciplinaire HAL, est destinée au dépôt et à la diffusion de documents scientifiques de niveau recherche, publiés ou non, émanant des établissements d'enseignement et de recherche français ou étrangers, des laboratoires publics ou privés. 


\section{Management on the basis of the best scientific data or integration of ecological research within management? Lessons learned from the northern spotted owl saga on the connection between research and management in conservation biology}

Running title: Spotted owl, Research and Management

Frédéric Gosselin

Cemagref, UR EFNO, F-45290 Nogent-sur-Vernisson, France

E-mail: frederic.gosselin@cemagref.fr

Fax: +33 2389503 44, Tel: +33 238950358

Published in Biodiversity and Conservation vol. 18, issue 4, pp.777-793

(doi: 10.1007/s10531-008-9449-6).

Available at

http://www.springerlink.com/content//8144t836x202478/ 
Abstract. The case of the Northern spotted owl (Strix occidentalis caurina) has now become a classic case study in conservation biology, characterized by a harsh social battle but also by the quantity and quality of the research performed. Based on this example, I study the way the research-management interface was organized. The main lessons I have learned were: 1 . laws that involve science in management are crucial but should be more precise; 2. scientific ad-hoc groups are useful reviewers of management plans and interpreters of the best scientific data available, even if more transparent scientific argumentation is needed on some points; 3 . in such applied cases, even science that has not been strongly integrated with management can produce results that are useful for management; 4. stronger links between science and management appear necessary, but difficult to implement. This last point makes me wonder whether environmental laws should not more frequently target the incorporation of science into the management process itself rather than "only" basing management on the best scientific data available. On a more ecological level, perhaps the habitat issue has been underrated during the last few years compared to other emerging threats such as the invasion of the spotted owl range by barred owls.

Keywords: adaptive management; demography; interface; monitoring; science-management coordination.

\section{Abbreviations:}

ESA: Endangered Species Act

FEMAT: Forest Ecosystem Management Assessment Team;

FS: United States Department of Agriculture Forest Service;

FWS: U.S. Department of the Interior Fish and Wildlife Service;

IUCN: International Union for Conservation of Nature;

ISC: Interagency Scientific Committee; 
NFMA: National Forest Management Act;

NWFP: Northwest Forest Plan;

NSO: Northern spotted owl (Strix occidentalis caurina, Merriam 1898);

USA or US: United States of America; 


\section{Introduction}

The case of the Northern spotted owl (Strix occidentalis caurina, Merriam 1898) has now become a classic case study in conservation biology. It was characterized by a harsh political and legal battle between environmental and industrial lobby groups, involving numerous lawsuits, and was finally partly solved by the Northwest Forest Plan in 1993. However, this case is also interesting because of the ecological research that was performed and the links between research and management it involved. I have remained fascinated by this case study since I did a training course in the United States of America (USA) on this issue while still a student from Europe. In this paper, I draw the six lessons I have learned with respect to the research-management interface. I will base my paper on the analysis proposed by Underwood (1995) on the relationships between ecological research and management in environmental issues. Underwood (1995) bases his analysis on the premise that ecological science as well as scientists have not been implicated enough in environmental management projects. He therefore proposes that research that is relevant to management - which he calls Category 1 Research - be taken into account when defining problems, posing questions and devising management proposals. Then, since ecology usually cannot guarantee that these proposals will work, he proposes that they should be considered as management hypotheses rather than "management solutions"; checking the results of these hypotheses requires some additional research, which he calls Category 2 Research (cf. Figure 1). Underwood (1995, p.240) discussed educational programs in managerial use of scientific information as a potential solution to make the research/management interface more efficient. Another perspective I will develop based on the spotted owl issue is the importance of laws in delineating the connection between management and science. Indeed, the USA federal laws regarding endangered species and the management of federal forests have tried to solve what Underwood pointed out as one of the basic difficulties in the use of ecological research in management: the lack of environmental managers' accountability for the way they integrate scientific knowledge into their decisions. This has been efficient in some 
respect (Lesson 1), even if in a haphazard fashion (Lesson 2 and Lesson 4). This has also made Category 1 Research crucial. Actually, Category 1 Research has been active and productive in the spotted owl case (Lesson 3), so much so that the new results were not all taken into account in the various reviews at the interface between research and management - especially the results that did not plainly confirm past management options (Lesson 5). Globally, the spotted owl issue is an example in which the interface between Category 1 Research and management was effective, despite difficulties. This is exemplified by the numerous arrows between Category 1 Research and Policy/Management in Figure 1. However, Category 2 Research, the one that accompanies the implementation of the management project, is still under-developed compared to Category 1 Research, and is very much lacking (cf. Lesson 6), thus confirming Underwood's analysis.

This paper focuses chiefly on a monodisciplinary - ecological - perspective but I think some of the lessons learned are also pertinent for more multidisciplinary endeavors. I will discuss some social scientists' points of view at the end of the paper. Also, I will encompass in the term "management" some aspects that are political.

\section{Setting the scene: a summary of the spotted owl issue:}

\section{Background}

The Northern spotted owl (NSO) is a subspecies of owl that lives in forests of the Pacific Northwestern states in the USA (California, Oregon and Washington) and in British Columbia in Canada. From the mid 1970's through the beginning of the 1990's, it progressively became the symbol of the threatened old-growth forests in this region because: (i) NSOs have a limited range; (ii) NSOs select mature and old-growth forests over other kinds of forests and (iii) the home range of one pair of NSOs is so huge - up to 1,000 ha - that protecting owl habitat has a great impact on forest management.

During the 1980's, federal agencies - both the United States (US) Department of Agriculture Forest Service (FS) and the US Department of the Interior Bureau of Land Management - proposed many 
successive management plans to provide owl habitat on federal lands. The issue at stake was partly whether or not this management would circumvent the listing of the NSO under the federal Endangered Species Act (ESA), a law that not only protects individuals of endangered species, but also their habitat. The proposed management plans changed over time according to successive scientific results, and according to the pressure from environmental lobby groups: from the preservation of parts of territories of individual owls to the preservation of clumps of several dozen individual territories and the management of the "matrix" between these clumps so that low habitat quality would not hinder dispersing owls (Noon and McKelvey 1996).

The early 1990's brought strong changes in the NSO issue. First, in 1989 and 1991, the environmental organizations obtained an injunction on all FS timber sales containing suitable NSO habitat, especially because the FS management directives violated the species viability requirement in the regulations (36 CFR §219.9) that implemented the National Forest Management Act (NFMA) at that time (Duncan and Thompson 2006; Noon and Blakesley 2006). The viability requirement specifies that the FS must plan national forests to provide for viable populations of all native and desired non-native vertebrate species in the planning area - usually considered to be the individual National Forest. These injunctions on timber sales were the beginning of a drastic reduction in timber harvesting on federal lands in the Pacific Northwest from 1990 to 1993.

In parallel, in June 1990, the U.S. Department of the Interior Fish and Wildlife Service (FWS) decided to list the NSO as threatened under the ESA, throughout its range, because of inadequate regulations, and population and habitat decline.

\section{The Forest Ecosystem Management Assessment Team and the Northwest Forest Plan}

In April 1993, as a result of promises made during the Presidential campaign, President Clinton asked a team mainly composed of federal and state scientists, called the Forest Ecosystem Management Assessment Team (FEMAT), to prepare a written report with options that could solve 
the NSO issue, considering not only the NSO, but also other species depending on the forest and including socio-economic considerations. It resulted in the Northwest Forest Plan (NWFP; cf. http://www.reo.gov/), which mostly concerned the federal forests in the NSO range. The main decisions made in this plan were:

(i) to transform most of the federal forests into different kinds of reserves: 1) riparian reserves, bands of variable width left untouched to protect riparian ecosystems; and 2) very large late-successional reserves - several dozen to hundreds of thousands of hectares -, whose aim is to allow the continued existence of old-growth forest habitat and of the numerous species associated with it. Overall, $77 \%$ of the forested federal land base was included in reserves;

(ii) to manage the remaining federal forests differently, with emphasis on securing "long" minimum rotation length, and on the retention of $15 \%$ of the trees during final cuts;

(iii) to try new ways of managing forests on about $5 \%$ of the federal land base in 10 Adaptive Management Areas. The aim of these areas was to encourage the development and testing of new technical and social approaches to achieving desired ecological, economic, and other social objectives - thus helping the long-term viability of the plan.

Under the NWFP, scientific teams organized the monitoring of NSO populations and habitat (Lint et al. 1999), and evaluated the success of the plan relative to the NSO over the first ten years (Lint 2005). Another team helped the FWS summarize the state of the knowledge relevant to the continued listing of the NSO under the ESA (Courtney et al. 2004). Actually, research on the NSO has remained active since the adoption of the NWFP (cf. Lesson 3). Especially, the analysis of ongoing demographic monitoring of several NSO populations shows that they are still declining, particularly in the Northern part of the range (Anthony et al. 2006). Finally, a Draft Recovery Plan was proposed in 2007 (U. S. Fish and Wildlife Service 2007) that has undergone a scientific review (http://www.fws.gov/pacific/ecoservices/endangered/recovery/pdf/Contract.pdf).

Other kinds of monitoring were also performed in the region under the NWFP, including socioeconomic monitoring (Charnley et al. 2006; Thomas et al. 2006). After the NWFP, the wood and 
forest management sectors had negative trends in the region, characterized by a stronger reduction in federal wood harvest rates and FS employment than expected in the NFWP. Since the harvest levels on private lands remained stable and did not compensate for the decreases on federal forests, employment in the wood forest sector decreased - slightly more strongly than predicted in the NWFP: 30,000 jobs were lost in the timber industry between 1990 and 2000. Nevertheless, only slightly more than one third of this decrease could be attributed to the NWFP (cf. also Freudenburg et al. 1998, for a longer term perspective on the link between wood industry employment and environment protection). On the whole, the economic effect on local communities was mixed, with some communities proving resilient, especially those along major transportation routes, and some communities experiencing significant economic shocks.

\section{Lesson 1: Laws that involve science in management are crucial}

The wandering road to the NWFP described above was not the beginning of the road: it was preceded by several cases where expert panels or scientific task forces had warned politicians of the long-term negative impact of continuing the management of the time (FEMAT 1993, chapter VII; Thomas et al. 1993). These warnings were apparently disregarded, until the new laws required management plans to be scientifically sound. Indeed, during the 1970 's, federal laws such as the ESA and the NFMA were adopted that were strong promoters of taking scientific knowledge into account during political and management decisions (Schultz and Gerber 2002; Noon and Blakesley 2006).

The implication of science in the political process is clear in the text of the ESA, particularly in the stages for determining whether to list a species:

"The Secretary shall make determinations required by subsection (a)(1) solely on the basis of the best scientific and commercial data available to him..."

and how to define the critical habitat for the species: 
"The Secretary shall designate critical habitat, and make revisions thereto, under subsection (a)(3) on the basis of the best scientific data available and after taking into consideration the economic impact, the impact on national security, and any other relevant impact, of specifying any particular area as critical habitat" (the stresses are ours).

The ESA seems to target a similar aim as Underwood (1995): promote "ecological research as a primary component of environmental decision-making, rather than an increasingly peripheral procedure". In the ESA, the Secretary of the Interior is the Scientific Authority and the process by which this "best scientific data" is taken into account is not specified (http://epw.senate.gov/esa73.pdf; Carroll et al. 1996). In the case of the NSO, these processes included the creation of numerous scientific ad-hoc groups (cf. Lesson 2), the meta-analyses of the demographic studies performed on the NSO (Anderson and Burnham 1992; Burnham et al. 1996; Franklin et al. 1999; Anthony et al. 2006) and the organization of scientific reviews of some of the documents (e.g. http://www.fws.gov/pacific/ecoservices/endangered/recovery/pdf/Contract.pdf). A more indirect way in which ecological research was taken into account in the management process was through the legal instability associated with management plans that were not scientifically credible (cf. examples in Duncan and Thompson 2006).

This implication of science in the political process was paralleled by the scientists' interest in these federal laws, as seen when counting the scientific publications that deal with these laws and their links to research or science. For example, a request on the ISI - Web of Science ${ }^{(\mathrm{TM})}$ based on the following keywords: ("endangered species act" OR "national forest management act") AND (research OR science* OR scientific), restricted to the period between 1994 and 2005 retrieved 83 references, whereas a request about comparable European directives: ("Natura 2000" OR "habitats directive" OR "habitat directive" OR "birds directive") AND (research OR science* OR scientific) during the same period yielded only 39 references. Although these figures must be interpreted with care, the discrepancy in publication level between Europe and the US is higher for this particular search than for more general requests associated to research or science in general (research OR science* OR scientific) or the field of biology or ecology (biolog ${ }^{*}$ OR ecolog $)$ : levels of publication 
were between 10 to $30 \%$ lower in Europe than in the US with these more general requests compared to more than $50 \%$ lower for the first more specific search. These figures seem to show a peak in scientific attention to laws related to conservation biology in the US as compared with Europe.

\section{Lesson 2: Scientific ad-hoc groups are useful reviewers of management plans and interpreters of the best scientific data available}

Despite this strong legislative armada, in the process of applying these laws, opposite conclusions about the viability of the NSO under alternative management scenarios were reached by federal managers - especially from the FS - and the various scientific ad-hoc groups that were temporarily and specifically created (Duncan and Thompson 2006). The reasons why two such divergent analyses resulted from the same laws were investigated by Duncan and Thompson (2006): apart from the lack of clear definitions of terminology and objectives in the legal texts (cf. Lesson 4 below), they found that the main reasons were differences in the techniques used e.g. to analyze population viability, differences in the scale of the analyses and the difficulty for forest management agencies - as for many large institutions - to introduce a change in the status quo.

Examples of scientific ad-hoc groups include the Interagency Scientific Committee (ISC; Thomas et al. 1990), and the FEMAT (FEMAT 1993). These scientific ad-hoc groups produced analyses, proposals and guidelines that generally took the state of scientific knowledge into account, in a way that differed according to the mandate of these groups (Courtney and Franklin 2004). In this respect, these groups acted both as reviewers of management plans as well as analyzers of the best scientific data available (arrows 2.2 and 2.1 in Figure 1).

The scientific ad-hoc groups had mixed success in obtaining sufficient agreement on their recommendations. Some of their plans were actually challenged in lawsuits, giving the impression of an unstable process: as stated by Duncan and Thompson (2006), "crisis management and angry voices have become the questionable norm". Again, this situation was partly related to the 
difference in the scale of analysis: most of the scientific ad-hoc groups targeted the viability of the NSO throughout its range in the USA - in agreement with the ESA -, while the environmental lobbies targeted the NSO viability at the National Forest scale - in line with the NFMA.

\section{Lesson 3: Even science which has not been strongly integrated with management (Category 1 Research) can produce results that are useful for management}

NSO scientists also proved useful since the beginning of the NFWP by the results they provided to management (Category 1 research). These results concern genetics and systematics, relations with prey, habitat associations and trends, the potential for interspecific competition with barred owls (Strix varia), and demography (cf. e.g. Courtney et al. 2004). In this paper, I will mainly focus on the question of habitat. Ongoing research on the population biology and demography of the NSO has revealed surprising new results on the population dynamics in relation to habitat and climate (Franklin et al. 2000; Olson et al. 2004). In terms of habitat, the main finding of Olson et al. (2004) (respectively Franklin et al. 2000) is that, in the regions studied, populations of NSOs have the potential of being viable only if they live in territories that mix old-growth, late-seral and mid-seral conifer forest (respectively spotted owl core habitat) with edges between these and younger forests. Other recent studies have more or less corroborated these results (on demographic data: Dugger et al. 2005; on occupancy data: Zabel et al. 2003; Pearson and Livezey 2003). The most obvious explanation of the results in Franklin et al. (2000) would be that the main prey of the NSO in this region, the dusky-footed woodrat (Neotoma fuscipes, Baird 1858), occupies either edges between old forests and young forests or young forests. This explanation does not hold for the area studied in Olson et al. (2004).

These results belong to Category 1 research rather than Category 2 research, because they were management relevant without being developed inside the management process. Here, 
the 'mere' collection of data without a clear randomized experimental design - through what is called mensurative experiments by Hurlbert (1984) and Krebs (1999) - and their clever interpretation did further our knowledge and produce the above results that question some of the assumptions behind the NWFP. Indeed, previous analyses on population growth rates of the NSO mostly tried to determine if, on average, the populations were declining or not - without any link with habitat variables. Franklin et al. (2000) purposefully included different shapes - including quadratic shapes - of the effect of habitat variables on demographic parameters. They also studied the impact of habitat quality not only on survival or fecundity rates but also on potential habitat fitness, a quantity close to a territory-level potential growth rate given the habitat quality of the territory.

These new results could also have depended on the ecological or management gradients being studied: should a study compare purely old-growth territories to purely young forest (respectively, occupied and unoccupied territories), the result would probably be a preference of the NSO for purely old-growth; but when territories mixing old forests with young stages are included (resp. only occupied territories are taken into account), it becomes possible to reveal a preference of NSOs for mixed territories (cf. Franklin et al. 2000).

\section{Lesson 4: Laws that involve science in management should be more precise}

Our first three lessons learned are rather positive relative to how NSO science developed and was taken into account in the NSO management process. Some problems have also been met in the NSO issue, three of which were identified as my final three lessons. One of the main hurdles that has been encountered in the case of the NSO are certain ill-defined points of law. For example, regulation 36 CFR $\S 219.9$ associated with the NFMA calls for native "species viability", but does not further define what is meant by "viability", contrary to e.g. IUCN categories (IUCN Species Survival Commission 2001). The same ill-definition of a "viable" population holds for the European "Habitats" directive

n92/43/EEC

(cf.

http://eur- 
lex.europa.eu/LexUriServ/LexUriServ.do?uri=CELEX:31992L0043:EN:HTML) and the ESA (Holsinger 1995). As a result, the viability requirement was interpreted very differently by forest managers and scientific ad-hoc groups (cf. also Lesson 2). Other terms in the Endangered Species Act are not clearly defined such as "habitat" or "critical habitat" (Murphy and Noon 1991), which also showed up in the NSO case as a problem in the 2007 Draft Recovery plan, as stressed by the scientific reviewers (cf. http://www.fws.gov/pacific/ecoservices/endangered/recovery/peer.html). The implications of the use of such ill-defined terms in environmental laws (respectively the NWFP) has been well analyzed by Murphy and Noon (1991) and Peterson (1993) (resp. Bormann et al. 2006), to which the reader is referred. This entails two specific roles for scientists in the management/research interface:

Lesson 4-1: provide managers and politicians with clear definitions and concepts, and if they are not clear, help clarify them (Murphy and Noon 1991);

and Lesson 4-2: question the definition of terms or the soundness of concepts used in the law or in the management process, or require that they be specified before scientists can answer questions (Underwood 1995, p.235, 240 and 244).

In the specific case of the NSO, scientists have contributed in some respect to these two tasks in the ad-hoc scientific groups or in the scientific review processes (cf. Lesson 2 and Discussion).

\section{Lesson 5: the interpretation of the "best scientific data available" is problematic}

According to Smallwood et al. (1999) and Hecht and Parkin (2001), another set of difficulties when trying to use the "best scientific data" comes from the lack of a strong, scientific reviewing process at different stages in the ESA. I do not think this remark is completely valid in the particular case of the NSO, given the numerous scientific ad-hoc groups created (cf. Lesson 2), which partly had the task of reviewing various management plans. However, specific difficulties were encountered when reviewing or taking into account the best scientific data available in some NSO cases. I will present 
these points in relation to the new results mentioned in Lesson 3. Similar points could have been made on the problem of dispersal behavior (Irwin and Wigley 1993; Harrison 1994; Harrison et al. 1993) or survival during dispersal (Boyce et al. 2005).

\section{Lesson 5-1: part of the relevant scientific literature is omitted or not properly}

\section{interpreted}

The NSO case shows some examples of scientific or management documents that do not take into account the relevant scientific data. Some of the recent core NSO documents (Anthony et al. 2006) did not consider the new habitat results mentioned in Lesson 3 (Franklin et al. 2000; Olson et al. 2004; Dugger et al. 2005).

In other cases, these results are very much incorporated and even central to the strategy (U. S. Fish and Wildlife Service 2007), but the results were not properly interpreted and some of the terms were not clearly defined (echoing Lesson 4). A scientific review helped to clarify this (http://www.fws.gov/pacific/ecoservices/endangered/recovery/peer.html).

\section{Lesson 5-2: the scientific literature is discussed in relation to only one}

\section{Category of habitat model}

The potential management implications of the findings presented in Lesson 3 are important: they show that the emphasis in the NWFP on big reserves of late-successional forests might have been suboptimal - at least in the southern part of the range and in the short term - compared to a strategy that would have mixed managed or disturbed forests with old-growth and late-successional reserves at a scale ranging from dozens to hundreds of hectares - a strategy relatively close to the original FS plans in the 1980's. To rephrase Noon and Blakesley (2006), hypothesis 2 of the ISC i.e. NSOs do not differentiate among forest types on the basis of age, structure or composition would still be rejected, but in favor of a different "best habitat" model from before. 
Therefore, I find it fair to recognize that we now have at least two different sets of "best habitat" models for the NSO: the model that mostly justified the NWFP - model 2.1: at the territory scale, the more territories concentrate old or old-growth forests, the greater the probability of NSO occupancy and the greater their potential fitness -, and the model that is related to the new results in Lesson 3 - model 2.2: at the territory scale, NSOs have greater occupancy rates and potential fitness in territories that mix (core) old (growth) forests with young forests (or edge or non-owl habitat). More precise models, giving shapes - linear, pseudo-threshold, quadratic... - and typical values for the coefficients could even be targeted - at least if a meta-analysis is performed on these issues.

However, recent reviews on the status of the NSO, taking these results into account either strongly (Courtney et al. 2004; U. S. Fish and Wildlife Service 2007) or marginally (Lint 2005), either recommend continuing the large late-successional reserve strategy, for other ecological reasons (Courtney et al. 2004; Lint 2005) or change the strategy to have more young stages inside large reserves (U. S. Fish and Wildlife Service 2007). Franklin et al. (2000: 578) and Olson et al. (2004: 1052) both agree more with a status quo in the reserve strategy since they propose that their results need further testing - through correlative analyses in other locations or through experimentation - before being applied in management. However, what is surprising is the lack of will in many documents to recognize that the habitat question has not been completely resolved so far, and that it might be as central as new threats, such as the interspecific competition with barred owls.

\section{Lesson 6: the necessity and difficulties of a stronger integration between science and management (Category 2 Research):}




\section{coordination, data collection and analysis, experimentation and adaptive management}

Research on the NSO has been relatively effective so far in providing results that are relevant to managers (Category 1 Research), e.g. about habitat selection, genetics, demography... Yet, the NSO is still listed and declining, and, as stressed by Courtney and Franklin (2004), greater coordination might be needed to increase efficiency:

"while the community of Spotted Owl researchers and managers have achieved much (notably the unprecedented coordination of the demographic studies), there is currently no central coordinating effort, and no systematic priority of research and monitoring needs, with a concomitant effort to acquire funding; for other listed species, a Recovery Team sometimes fills this coordinating role. Some important and potentially critical information (e.g. on genetics, taxonomy, habitat effects on demography, prey relations, and Barred Owls) has been collected as a consequence of the initiative of individual researchers. Again, this is commendable, but hardly a prescription for moving forward, or more importantly improving the conditions for the owl through knowledge-based management such that the owl can be delisted. Recognition of the need for a coordinating position or body might significantly advance Spotted Owl conservation and management". (Courtney and Franklin 2004)

Yet, some kind of coordinating body does exist and is active: the NSO "effectiveness monitoring module" under the NWFP (Lint et al. 1999; Lint 2005). It might have been limited by its means or by its very mandate, that separated too much demography and habitat:

"The primary goal of owl monitoring is to evaluate the success of the Plan in arresting the downward trend in spotted owl populations and in maintaining and restoring the habitat conditions necessary to support viable populations of the northern spotted owl on federallyadministered forest lands throughout the owl's range". (http://www.reo.gov/monitoring/reports/10yr-report/northern-spotted-owl/index.shtml) 
Here, the study of the link between habitat and demography of the NSO appears secondary and exploratory.

This weakness of the coordinated science-management planning is apparent in the lack of suitable data, e.g. to globally analyze the impact of habitat quantity and quality on demographic rates (Courtney and Franklin 2004; Boyce et al. 2005) or to distinguish in non-owl habitat between mature hardwood forests, young successional forests following timber harvesting and those following a natural disturbance (Franklin et al. 2000). This lack of data resulted in a series of four meta-analyses that studied the demography of the NSO, but not its relationship with habitat quality (Anderson and Burnham 1992; Burnham et al. 1996; Franklin et al. 1999; Anthony et al. 2006). Some of these reports called for collection of better data (recommendations 1 and 2 in Franklin et al. 1999 and recommendation 6 in Anthony et al. 2006). This lack of suitable data seems to be a persistent difficulty and contradicts the initial monitoring strategy (Lint et al. 1999) and the expectations of scientists outside the NSO issue:

"Population monitoring should be continued, but rather than simply documenting the decline of populations, its focus should now be to monitor the impacts of efforts to reverse the decline and of the new management scheme proposed for old-growth forests" (Holsinger 1995, p. S-14)

and

"With the massive amount of demographic data that exist for the spotted owl, it must be possible to test whether its decline is associated with habitat loss, barred owls, both, or an interaction between twe (http://www.fws.gov/pacific/ecoservices/endangered/recovery/pdf/Contract.pdf).

However, what is the most striking on this issue is the last sentence of the last meta-analysis:

"If we are going to be able to understand the relative influence of habitat alterations, barred owls, climate, and other factors on spotted owl populations, future analyses will need more 
detailed data on these factors. We strongly encourage researchers to examine these relations in their individual study areas, as the complexity of these analyses may be beyond the scope of any meta-analysis on all areas combined" (Anthony et al. 2006, p.35).

Whereas some people (e.g. Boyce et al. 2005), including myself, believe that only a meta-analysis could treat this question with the available NSO data, the authors of the meta-analysis themselves state that it "may be beyond the scope of any meta-analysis on all areas combined" (actually in contradiction with their recommendation n4). The reasons for this potential impossibility are not given: is it due to a lack of means, to the time constraints of meta-analyses, to the lack of a coordinating body, to an unclear mandate, to an unwillingness to have the NSO and NWFP issues reopened?... Though one can understand the relative complexity of collecting suitable habitat data throughout the range of the NSO, it still seems strange to me that a meta-analysis could not treat more simple questions such as the impact on NSO demography and/or occupancy probability of matrix or late-successional reserves, climate, or topography - possibly in interaction with barred owls as suggested by the results of Pearson and Livezey (2003). The origin of this problem should be clarified, for the conservation of the NSO but also for other conservation issues.

However, correlative data analysis will not answer the answer completely, and NSO scientists call for more landscape-level experimental management to better identify the causes of the NSO's decline (e.g. Irwin and Wigley 1993; Franklin et al. 2000; Courtney and Franklin 2004; Lint 2005; Noon and Blakesley 2006; Gutiérrez et al. 2007; see also http://www.fws.gov/pacific/ecoservices/endangered/recovery/pdf/Franklin.pdf). Indeed, it is not known precisely if the ongoing NSO decline is due to a time-lag effect of past habitat decline - the main mechanism targeted in the NWFP - or if other causes are involved (Noon and Blakesley 2006). The ecological processes or management actions targeted by experimentation would be: interspecific competition with barred owls, prey base, small diameter thinnings and total restriction on the harvest of large-diameter trees (Noon and Blakesley 2006). Given the results mentioned in Lesson 3 and the analyses in Courtney and Franklin (2004), it seems particularly valuable to add the habitat quality issue to this list; this aspect could be tested by carrying out a limited amount of 
cutting to mimic natural disturbances inside NSO territories. This could be coupled with barred owl and prey experiments.

This kind of experimental management as well as the "knowledge-based management" called for by Courtney and Franklin (2004; cf. above) are very close to active adaptive management, a form of adaptive management based on experimentation (Walters and Holling 1990), and to Category 2 Research of Underwood (1995). Adaptive management is, in part, an endeavor to better integrate science into management by trying to learn from the management process itself. In this article, I do not have the space to further investigate the pros and cons of adaptive management in general (treated in e.g. Walters and Holling 1990; Stankey et al. 2003; Stankey 2003), but I would like to stress a few points related to the Pacific Northwest experience. Adaptive management is indeed one of the major originalities of the NWFP, as well as one of the least successful so far (Pipkin 1998). A review of the work done in the Adaptive Management Areas (cf. Stankey et al. 2003; Stankey 2003) highlights the following difficulties encountered:

(i) adaptive management does not mean the same thing to the different people involved; this lack of a common definition engendered difficulties in defining the training necessary for it, as well as the objectives and indicators used to assess whether something had been learned... Also, some managers have not realized, or are not convinced, that the formalization of learning as a management objective makes a difference in the current situation;

(ii) the culture of both the FS and the Bureau of Land Management, the two main agencies involved, is marked by prescriptive approaches and standardized rules which greatly constrain innovations and makes the work of the Adaptive Management Area coordinators more difficult (Gray 2000);

(iii) there has been no strong administrative support from the agencies: coordinators have been designed for each Adaptive Management Area, but they lack the means to do the job, in terms of objectives from the hierarchy, budget, training, support staff, time allocated to coordination, and awards. "It meant that the role of the coordinators as advocates and champions of adaptive 
management was severely diminished. The literature stresses the importance of such advocates" (Stankey 2003). Adaptive management therefore is not "on the radar screen" for many managers;

(iv) this lack of institutional involvement can be accounted for by a legal, political and economic background that forces the agencies to be risk-averse. This difficulty could have been overcome by negotiations between managers and the regulatory instances to define conditions where "risky" experiments could be undertaken. On a more political side, "it is also possible that, because of the relative calm brought by the NWFP in the wake of such contentious ideological battles, many people simply do not want to revisit the issues and refine or modify approaches" (Gray 2000);

(v) finally, there is a need to build - or to integrate - functional social networks, including scientists, managers and citizens, before adaptive management can be efficient (Gray 2000; cf. also Callon and Rabeharisoa 2003). This either means that adaptive management will take time to become efficient, or that it can only become efficient quickly in conditions where such networks are already working.

It is clear from the above elements that Adaptive Management faces important difficulties when put into practice. These difficulties are mostly non-scientific - administrative, managerial, political, legal, cultural, social and economic (cf. also Walters 1997; Rogers 1998). However, Stankey (2003) and Pipkin (1998) still promote a more ambitious endeavor, in which significant institutional, managerial and cultural shifts are made to facilitate the emergence of adaptive management.

\section{Discussion}

On the usefulness of taking ecological research results into account in management projects 
Going back to Underwood (1995)'s analysis, some authors are very pessimistic about the usefulness of environmental research in management projects (cf. Hammond et al. 1983 and other papers quoted by Underwood 1995, pp. 242-243). I agree with Hammond et al. (1983) that the translation of scientific results into the policy framework encounters problems relative to differences in scope, language and levels of uncertainty (cf. also Roqueplo 1999). However, as stressed in Lesson 1 and following Underwood (1995) and Roqueplo (1999), I think that taking science into account in the NWFP has been useful in some respects. For example:

- the Agencies had to take into account the maintenance of NSO habitat as a real objective (cf. Lesson 1 and Lesson 2);

- $\quad$ knowledge on NSO habitat is increasing (cf. Lesson 3);

- the demographic meta-analyses informed managers on the population trend of the NSO.

Other authors have already tackled the potential limitations of integrating science and environmental management, with regard to uncertainty (Ludwig et al. 1993; Underwood 1995) and scope and language (Underwood 1995; Rogers and Biggs 1999; Roqueplo 1999; cf. also Lesson 4). I will not reiterate them here.

\section{Alternatives to ad-hoc temporary scientific groups}

On the whole, despite their mixed success in producing viable management plans and despite Lesson 5 (cf. following), I agree with Duncan and Thompson (2006) that the scientific ad hoc groups were useful catalysts for the integration of scientific results into the management sphere. As small, temporary institutions highlighting a different part of the ecological context, they were effective in destabilizing the dominant, resource-extraction based culture of the forest management agencies, and in introducing change. They analyzed the available scientific results and reviewed the management plans, which are, according to Underwood (1995), two key roles roles for ecological 
scientists in the management process. In this respect, the NSO case is an example of how scientists might be involved in management projects.

However, ad-hoc temporary scientific groups should be questioned with respect to their composition, their way of working and their permanence. Perhaps the mostly pure scientific composition of these groups was justified in this case by the considerable economic and political pressures: any mixed group would either have had difficulties maintaining scientific considerations in the forefront or would have been judged as suspect. However, groups mixing researchers with managers or citizens could promote the long-term viability of the project (e.g. Bormann et al. 1999), as well as the efficient dissemination of knowledge and an even stronger involvement of research (Callon and Rabeharisoa 2003; Joly 2007). This is partly what has been tried in Adaptive Management Areas, with mixed success (cf. Lesson 6).

Joly (2007) also insisted on the frequently uncritical behavior of scientists when it comes to adopting collective public points of view. Possibly, some adjustments in the way these teams work could make the process more robust with regard to this "judgement bias" (cf. Lesson 5), for example by organizing the process as a judicial trial or legal expertise - with experts in charge of defending contradictory points of views (Roqueplo 1999) - or by developing either a "hybrid forum", mixing experts and non-experts, or a "second circle of expertise" (e.g. a Citizens conference) (Joly 2007). Also, the use of systematic review techniques (Pullin and Stewart 2006) could help make the summary of the knowledge more objective still.

Another point that emerged from this case study is the need for permanent scientific groups instead of temporary ones. Such permanent groups, named Recovery Teams, can be created within the framework of the ESA. This was not the case for the NSO and partly explains the lack of scientific coordination in the issue (Courtney and Franklin 2004; cf. Lesson 6). Such a group could be responsible for producing demographic and territory occupancy meta-analyses that are more related than is currently the case to the hypotheses behind the NWFP (cf. Lesson 6). 
In other cases, the temporary involvement of scientists or of scientific institutions proved useful, with no apparent need for scientist ad-hoc groups. An example of this type was the scientific review of the Draft Recovery plan (cf. U. S. Fish and Wildlife Service 2007). This process showed that the Draft Recovery plan improperly interpreted the habitat results presented in Lesson 3, among other things for reasons of inappropriate spatial scale. This provides a good illustration of the statement by Underwood (1995, p.235) that "only research ecologists can sensibly advise on the applicability of the available (Category 1 ) research to the problem being addressed".

\section{Should laws target Category 1 or Category 2 Research?}

To come back to Underwood's scheme, what seems clear is that the ESA strongly stresses the correct incorporation of Category 1 Research in the management process (cf. Lesson 1). The ESA is relatively silent on Category 2 Research. In Europe, the Habitats Directive targets the future production of scientific knowledge relevant to the Directive, a rather unclear mix of Category 1 and Category 2 Research.

The NSO issue appears to be a very good example of what ecological research can produce when mostly performed inside Category 1 research. It does actually produce useful results (cf. Lesson 3), but whose lack of integration with the management and decision processes limits their applicability in the management sphere (Lesson 6). Indeed, some Category 2 research has been performed, through the monitoring of the NSO population trend. Unfortunately, the result is a persistent declining trend, and a lack of further Category 2 research that could explain this trend. I therefore interpret this as a clear example of the need for Category 2 research in conservation biology projects.

Based on this example, I wonder whether laws on the conservation of biodiversity - e.g. the ESA and the Habitats Directive - should not also include means or obligations on the production of new knowledge inside the management process itself as proposed by Underwood (1995), to evaluate 
management hypotheses through monitoring, experimentation and analysis of data (cf. also Rogers and Biggs 1999). This new knowledge would target the objectives of the laws - possibly made more precise (cf. Lesson 4) - by specifying further what defines "critical habitat" in the case of the ESA or by requiring population level data before judging the favorable conservation status of species inside the Habitats Directive. As stressed by Underwood (1995), ecologists have a strong responsibility here: instead of hiding behind - and even sometimes promoting - apparently consensual but actually unclear terms that can negatively affect the management process, we should battle for clearer definitions and concepts (cf. Lesson 4 as well as Underwood 1995, p.244). Instead of developing management solutions, we should insist that management alternatives be considered as hypotheses. Instead of basing the management process on social consensus only, we should stress the unsurpassed value of different kinds of monitoring and experimentation (cf. Figure 1), inside the management process. I agree that this target of more strongly integrating ecological research inside the management process is difficult; but I believe the NSO case study calls for laws - or at least management processes - that move in this direction.

\section{Conclusions}

In conclusion, the four main lessons I have learned from the NSO issue can be summarized as follows:

1. Laws that involve science in management are crucial (Lesson 1) but should be made more precise (Lesson 4);

2. Scientific ad-hoc groups are useful reviewers of management plans and interpreters of the best scientific data available (Lesson 2), although there is a need for more transparent scientific argumentation on some aspects (Lesson 5), and also a need for more permanent scientific groups, possibly even for opening up some of these groups to non-scientists; 
3. In such applied cases, even science which has not been strongly integrated with management (Category 1 Research) can produce results that are useful for management (Lesson 3);

4. However, some scientists are calling for stronger coordination of research efforts on the NSO: given the continuing decline of the NSO and the uncertainty about the causes of this decline, a stronger integration between science and management appears necessary; even though difficult to implement, it could include more integrated data collection - especially between data on NSO demography, habitat quality and quantity and barred owl density - and active adaptive management (Lesson 6). This makes me wonder whether environmental laws should not more frequently target the incorporation of science into the management process itself - Category 2 Research - rather than "only" basing management on the best scientific data available (cf. Discussion).

Acknowledgements. This work was supported by ALTER-Net (A Long-term Biodiversity, Ecosystem and Awareness Research Network). ALTER-Net (http://www.alter-net.info/www.alternet.info) is a Network of Excellence funded by the 6th Framework Programme of the European Commission. The initial work on this paper was part of Work Package 1.5 of ALTER-Net. A previous version of this paper was published in French in Responsabilité Environnement (Annales des Mines) (2006, vol. 44, pp. 43-49). Special thanks to Victoria Moore for her help in improving the English style and Frédéric Archaux for his useful remarks. 


\section{References:}

Anderson DR, Burnham KP (1992) Demographic analysis of northern spotted owl populations. In:

U.S. Fish and Wildlife Service (ed) Final draft recovery plan for the northern spotted owl. Portland, Oregon, USA, pp 66-75

Anthony RG, Forsman ED, Franklin AB et al (2006) Status and trends in demography of northern spotted owls, 1985-2003. Wildlife Monogr 163(1):1-48

Bormann BT, Martin JR, Wagner GH et al (1999) Adaptive management. In: Sexton WT et al. (ed)

Ecological stewardship. A common reference for ecosystem management. Elsevier, Oxford, England, pp 505-534

Bormann BT, Lee DC, Kiester AR et al (2006) Chapter 3: Synthesis: Interpreting the Northwest Forest Plan as More Than the Sum of Its Parts. In: Haynes RW et al. (ed) Northwest Forest PlanThe First 10 Years (1994-2003): Synthesis of Monitoring and Research Results. U.S. Department of Agriculture, Forest Service- Pacific Northwest Research Station, Portland, Oregon, pp 23-48 Boyce MS, Irwin LL, Barker R (2005) Demographic meta-analysis: synthesizing vital rates for spotted owls. J. Appl. Ecol. 42(1):38-49

Burnham KP, Anderson DR, White GC (1996) Meta-analysis of vital rates of the Northern Spotted Owl. Studies in Avian Biology 17:92-101

Callon M, Rabeharisoa V (2003) Research "in the wild" and the shaping of new social identities. Technology in Society 25(2):193-204, doi:10.1016/S0160-791X(03)00021-6

Carroll R, Augspurger C, Dobson A et al (1996) Strengthening the use of science in achieving the goals of the endangered species act: An assessment by the Ecological Society of America. Ecol Appl 6(1):1-11 
Charnley S, Donoghue EM, Stuart C et al (2006) Northwest Forest Plan-the first 10 years (19942003): socioeconomic monitoring results. Volume I: key findings. PNW-GTR 649-VOL. I. USDA Forest Service, Pacific Northwest Research Station, Portland, OR.

Courtney SP, Franklin AB (2004) Information needs. In: Courtney SP et al. (ed) Scientific evaluation of the status of the Northern Spotted Owl. Sustainable Ecosystem Institute, Portland, Oregon, p 121

Courtney SP, Blakesley JA, Bigley RE et al (2004) Scientific evaluation of the status of the Northern Spotted Owl. Sustainable Ecosystem Institute, Portland, Oregon

Di Stefano J (2004) The importance of ecological research for ecosystem management: The case of browsing by swamp wallabies (Wallabia bicolor) in commercially harvested native forests. Ecological Management and Restoration 5(1):61-67, doi:10.1111/j.1442-8903.2004.00170.x Dugger KM, Wagner F, Anthony RG et al (2005) The relationship between habitat characteristics and demographic performance of Northern Spotted Owls in Southern Oregon. Condor 107(4):863878, doi:10.1650/7824.1

Duncan SL, Thompson JR (2006) Forest Plans and ad hoc scientist groups in the 1990s: Coping with the Forest Service viability clause. Forest Policy Econ 9(1):32-41

FEMAT (1993) Forest ecosystem management: an ecological, economic and social assessment. Report of the FEMAT (Forest Ecosystem Management Assessment Team). U.S. Government Printing Office, Washington, D.C.

Franklin AB, Anderson DR, Gutiérrez RJ et al (2000) Climate, habitat quality, and fitness in Northern Spotted Owl populations in northwestern California. Ecol Monogr 70(4):539-590 Franklin AB, Burnham KP, White GC et al (1999) Range-wide status and trends in northern spotted owl populations. Colorado Cooperative Fish and Wildlife Research Unit and Oregon Cooperative Fish and Wildlife Research Unit, U. S. Geological Survey - Biological Resources Division, Fort Collins, Colorado and Corvallis, Oregon, USA

Freudenburg WR, Wilson LJ, O'Leary DJ (1998) Forty years of spotted owls? A longitudinal analysis of logging industry job losses. Sociological Perspectives 41(1):1-26 
Gray AN (2000) Adaptive ecosystem management in the Pacific Northwest: a case study from coastal Oregon. Conserv Ecol 4(2):6

Gutiérrez RJ, Cody M, Courtney S et al (2007) The invasion of barred owls and its potential effect on the spotted owl: a conservation conundrum. Biol Invasions 9(2):181-196

Hammond KR, Mumpower J, Dennis RI et al (1983) Fundamental obstacles to the use of scientific information in public policy making. Technological Forecasting and Social Change 24:287-297, doi:10.1016/0040-1625(83)90001-X

Harrison S, Stahl A, Doak D (1993) Spatial models and spotted owls - exploring some biological uissues behind recent events. Conserv Biol 7(4):950-953

Harrison S (1994) Metapopulations and conservation. In: Edwards PJ et al. (ed) Large-scale ecology and conservation biology. Blackwell, Oxford (UK), pp 111-128

Hecht A, Parkin MJ (2001) Improving peer review of listings and recovery plans under the Endangered Species Act. Conserv Biol 15(5):1269-1273

Holsinger KE (1995) Population biology for policy makers. Bioscience 45(Supplement):S10-S20

Hurlbert SH (1984) Pseudoreplication and the design of ecological field experiments. Ecol Monogr $54: 187-211$

Irwin LL, Wigley TB (1993) Toward an experimental basis for protecting forest wildlife. Ecol Appl 3(2):213-217

IUCN Species Survival Commission (2001) IUCN Red List Categories and Criteria. Version 3.1. IUCN, Gland, Switzerland

Joly PB (2007) Scientific expertise in public arenas: Lessons from the French experience. Journal of Risk Research 10(7):905-924, doi:10.1080/13669870701504533

Krebs CJ (1999) Ecological methodology. Benjamin Cummings, Menlo Park, California Lint JB, Noon BR, Anthony R et al (1999) Northern spotted owl effectiveness monitoring plan for the Northwest Forest Plan. USDA, Forest Service, Pacific Northwest Research Station, Portland, Oregon 
Lint J (2005) Northwest Forest Plan — the first 10 years (1994-2003): status and trends of northern spotted owl populations and habitat. USDA Forest Service, Pacific Northwest Research Station, Portland, Oregon

Ludwig D, Hilborn R, Walters C (1993) Uncertainty, resource exploitation, and conservation: lessons from history. Science 260(5104):17-18

Murphy DD, Noon BR (1991) Coping with uncertainty in wildlife biology. Journal of Wildlife Management 55(4):773-782

Noon BR, Blakesley JA (2006) Conservation of the northern spotted owl under the northwest forest plan. Conserv Biol 20(2):288-296

Noon BR, McKelvey KS (1996) Management of the spotted owl: A case history in conservation biology. Annu Rev Ecol Syst 27:135-162

Olson GS, Glenn EM, Anthony RG et al (2004) Modeling demographic performance of northern spotted owls relative to forest habitat in Oregon. Journal of Wildlife Management 68(4):1039-1053 Pearson RR, Livezey KB (2003) Distribution, numbers, and site characteristics of spotted owls and barred owls in the cascade mountains of Washington. J Raptor Res 37(4):265-276 Peterson CH (1993) Improvement of environmental impact analysis by application of principles derived from manipulative ecology - lessons from coastal marine. Australian Journal of Ecology $18(1): 21-52$

Pipkin J (1998) The Northwest Forest Plan revisited. USDI, Office of Policy Analysis, Pullin AS, Stewart GB (2006) Guidelines for systematic review in conservation and environmental management. Conserv. Biol. 20(6):1647-1656, doi:0888-8892 ISI:000242724500015 Rogers K, Biggs H (1999) Integrating indicators, endpoints and value systems in strategic management of the rivers of the Kruger National Park. Freshwater Biol 41(2):439-451, doi:10.1046/j.1365-2427.1999.00441.x

Rogers K (1998) Response to Walters 1997. "Challenges in adaptive management of riparian and coastal ecosystems": Managing Science/Management Partnerships: A Challenge of Adaptive Management. Conserv Ecol 2(2):resp1 
Roqueplo P (1999) Entre savoir et décision, l'expertise scientifique. INRA Editions, Paris

Schultz CB, Gerber LR (2002) Are recovery plans improving with practice? Ecol Appl 12(3):641-647

Smallwood KS, Beyea J, Morrison ML (1999) Using the best scientific data for endangered species conservation. Environ Manage 24(4):421-435

Stankey GH, Bormann BT, Ryan C et al (2003) Adaptive management and the Northwest Forest Plan - Rhetoric and reality. J. Forestry 101(1):40-46

Stankey GH (2003) Adaptive management at the regional scale: breakthrough innovation or mission impossible? A report on an American experience. In: Wilson BP, Curtis A (ed) Agriculture for the Australian Environment. Proceedings of the 2002 Fenner Conference on the Environment, July 30 to August 1 ,. Johnstone Centre, Charles Sturt Univeristy, Albury, pp 159-177 Thomas JW, Forsman ED, Lint JB et al (1990) A conservation strategy for the northern spotted owl: report of the interagency Scientific Committee to address the conservation of the northern spotted owl. USDA Forest Service and National Park Service, Portland, Oregon

Thomas JW, Franklin JF, Gordon J et al (2006) The Northwest Forest Plan: Origins, components, implementation experience, and suggestions for change. Conserv Biol 20(2):277-287, doi:10.1111/j.1523-1739.2006.00385.x

Thomas JW, Raphael MG, Anthony RG et al (1993) Viability assessments and management considerations for species associated with the late-successional and old-growth forests of the Pacific Northwest. Research Report of the Scientific Analysis Team. USDA Forest Service, Washington, D.C.

U. S. Fish and Wildlife Service (2007) 2007 Draft Recovery Plan for the Northern Spotted Owl (Strix occidentalis caurina): Merged options 1 and 2. U. S. Fish and Wildlife Service, Portland, Oregon Underwood AJ (1995) Ecological research and (and research into) environmental management. Ecol Appl 5(1):232-247

Walters CJ, Holling CS (1990) Large-scale management experiments and learning by doing. Ecology 71(6):2060-2068 
Walters CJ (1997) Challenges in adaptive management of riparian and coastal ecosystems.

Conserv Ecol 1(2)

Zabel CJ, Dunk JR, Stauffer HB et al (2003) Northern spotted owl habitat models for research and management application in Calfornia (USA). Ecol Appl 13(4):1027-1040 
Figure 1. Relationships between ecological research and the decision-making process inside an environmental management project (inspired from Underwood 1995 and Di Stefano 2004). Solid arrows indicate direct, initial and usual links. Open arrows indicate feedback links. Dotted solid arrows indicate potential direct links, which are not frequent. Green and bold typing is used to display lessons learned corresponding to processes that worked well in the case of the Northern spotted owl, red and italic typing being used for the opposite situation. The list of the lessons learned is the following:

L1: laws that involve science in management are crucial;

L2: scientific ad-hoc groups are useful reviewers of management plans and interpreters of the best scientific data available;

L3: even science which has not been strongly integrated with management (Category 1 Research) can produce results that are useful for management;

L4-1: scientists should provide managers and politicians with clear definitions and concepts and, if they are not, help clarify them (Murphy and Noon 1991);

L4-2: scientists should question the definition of terms or the soundness of concepts used in the law or in the management process, or require that they be specified before scientists can answer questions (Underwood 1995, p.235, 240 and 244);

L5: the interpretation of the "best scientific data available" is problematic;

L6: a stronger integration between science and management appears both necessary and difficult (Category 2 Research: coordination, data collection and analysis, experimentation and adaptive management).

Underwood (1995) identified two other categories of research that are not displayed: Research 3 was to develop new ecological process-level models or knowledge in case management failed. I have more or less included it in Category 2 research that should also target processes wherever appropriate. If, on the contrary, more fundamental ecological research is needed, its place might be 
outside a graph of the interface between research and management. Research 4 was qualified "managerial" and actually included two things: an analysis by ecological scientists of how ecological information was used by managers to reach their decisions, which I will discuss as part of the connection between Category 1 research and management (cf. Lesson 2 and discussion); and research done by social scientists on the way the management decision process works (cf. discussion). 


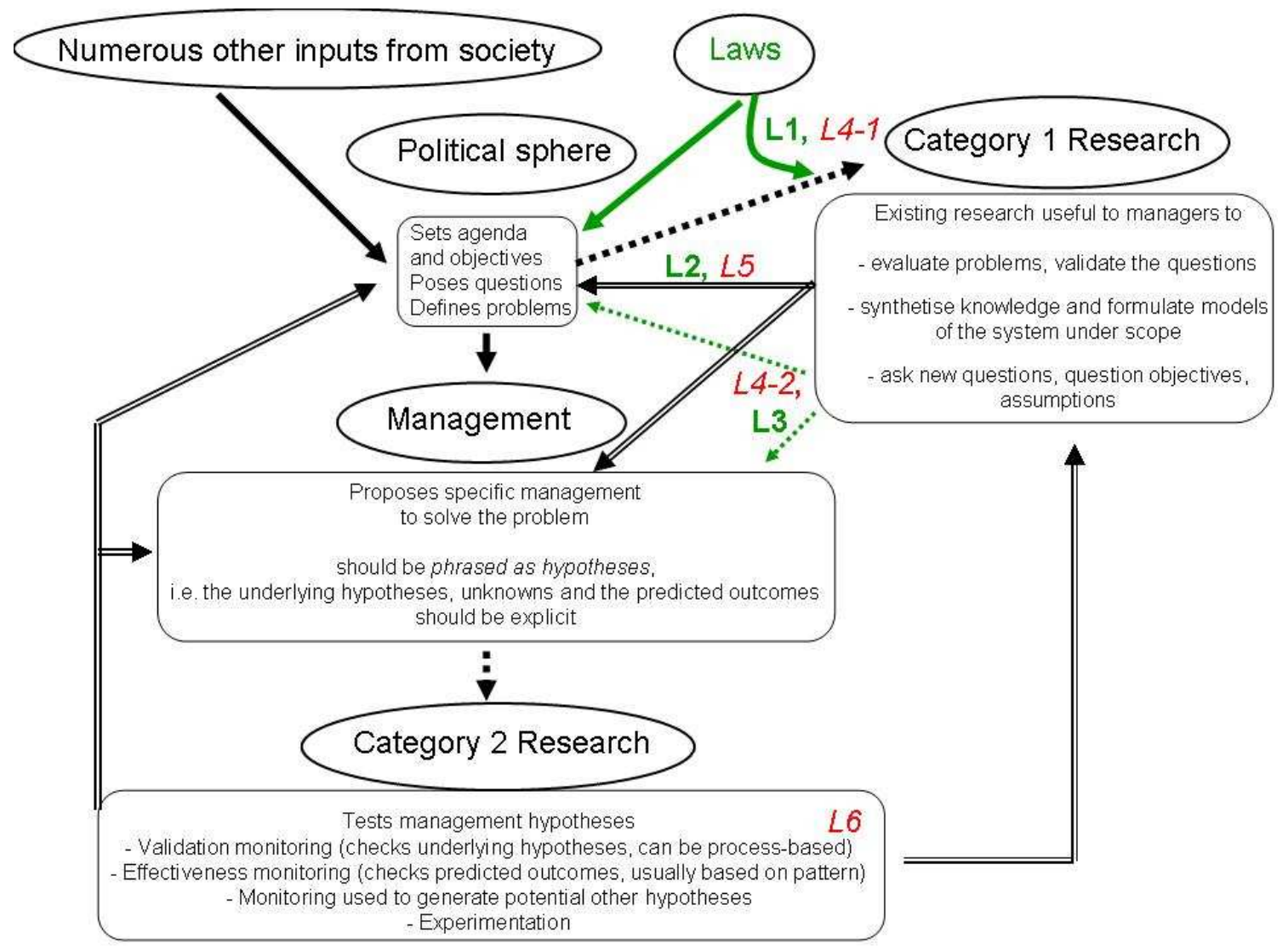

